\title{
Un ciclo de canciones federales \\ Las representaciones de Rosas y su época en la música popular de la primera mitad del siglo $\mathrm{XX}^{1}$
}

\author{
A cycle of federal songs \\ The representations of Rosas and his time in popular \\ music of the first half of the 20th century
}

Leandro Pankonin ${ }^{2}$

\section{Resumen:}

En el presente artículo analizaremos las representaciones sobre la figura de Rosas y su época, producidas desde la música popular, entre fines de los años veinte y la década de 1940. Trabajaremos en particular el ciclo de canciones federales, que tuvo por figura central -aunque no exclusiva- a Ignacio Corsini. A partir de su análisis buscaremos profundizar en la manera en que pudieron haber interactuado los imaginarios nacionales, la música popular y el problema de los usos del pasado durante ese ciclo. En particular, buscaremos integrar este repertorio de canciones, dado lo prolífico y popular que fue, en una mirada integral sobre la manera en que aquella sociedad pudo haber construido sus representaciones sobre la época de Rosas.

Palabras clave: música popular; representaciones del pasado; Ignacio Corsini; Rosas

\begin{abstract}
:
In this article we will analyze the representations about the figure of Rosas and his time, produced from popular music, between the late 1920s and the 1940s. We will work in particular on the federal song cycle, which had Ignacio Corsini as its central figure, although not exclusively. Based on its analysis, we will seek to delve into the way in which national imaginaries, popular music and the problem of past uses could have interacted during that cycle. In particular, we will seek to integrate this repertoire of songs, given how prolific and popular it was, in a comprehensive look at the way in which that society could have built its representations on the time of Rosas.
\end{abstract}

Keywords: popular music; representations of the past; Ignacio Corsini; Rosas

\footnotetext{
${ }^{1}$ Artículo recibido el 15/09/2020. Aceptado el 23/11/2020.

2 Consejo Nacional de Investigaciones Científicas y Técnicas. Contacto: leandro_ pankonin@yahoo.com.ar
} 


\section{Introducción}

En este artículo analizaremos las representaciones sobre la figura de Rosas y su época, producidas desde la música popular, entre fines de los años veinte y la década de 1940. Trabajaremos en particular el ciclo de canciones federales, que tuvo por figura central -aunque no exclusiva- al «caballero cantor» Ignacio Corsini. A partir del análisis de esa obra buscaremos saber algo más sobre la manera en que pudieron haber interactuado los imaginarios nacionales, la música popular y el problema de los usos del pasado durante el ciclo.

Para analizar la primera dimensión nos apoyaremos en los aportes de Anthony D. Smith (2009), quien ha llamado la atención sobre el rol que memorias, valores, mitos, símbolos y tradiciones compartidas han tenido en la construcción y reactualización de las naciones y los nacionalismos. En consonancia con dicho planteo, retomaremos dos cuestiones presentes en su abordaje. En primer lugar la afirmación de que estos elementos, lejos de haber sido simplemente «inventados» desde el Estado moderno, tienen necesariamente cierta «resonancia» o «eco» previo, en algún sector de la población. Y en segundo lugar, el rol que los artistas populares tienen, $y$ han tenido, para actualizar, crear, interpretar $y$ reinterpretar las imágenes que hacen posible imaginar la nación para grandes públicos. Smith apuntó que la popularidad que las imágenes puedan tener depende -en parte- de las «resonancias» $\mathrm{y}$ «ecos» que pudieran generar en aquellos/as que las consuman.

Respecto a la segunda dimensión, retomamos lo planteado por Simón Frith, quien afirmó que la música popular «no es popular porque refleje algo, o porque articule auténticamente algún tipo de gusto o experiencia popular, sino porque crea nuestra comprensión de lo que es la popularidad» (Smith, 2009, p. 30-33). Partiendo de ese enunciado ha propuesto un acercamiento a la música popular, considerada «más como constructo que como expresión de un colectivo» (Frith, 2001, p.418-420). Sin desconocer que se juegan, en particular, a partir del siglo XX, elementos de mediación orientados por los intereses de mercado, que intervienen sin duda en toda la cadena de producción de la música como bien de consumo, los «gustos en la música popular no se derivan simplemente de nuestras identidades socialmente construidas; también contribuyen a darles forma» (Frith, 2001, p.434). Este elemento resulta especialmente importante si tenemos en cuenta los géneros musicales que el 
ciclo federal puso en escena, en una coyuntura signada por la búsqueda de expresiones estéticas que abonaran a imaginar la nación.

La tercera dimensión será tratada en diálogo con la producción de Alejandro Cattaruzza (2017), quien con ánimo de construir una mirada integral sobre las formas de usar el pasado, y prestando especial atención a lo sucedido durante la primera mitad del siglo XX, remarcó que:

durante el período de entreguerras podía verse la lenta consolidación de otro centro posible para la tradición argentina. Hasta los centenarios, Mayo aparecía en soledad; (...) funcionaba simbólicamente como episodio fundacional de la tradición política nacional, aquella que era específicamente argentina. Aquel otro centro posible de la argentinidad se rastreaba en producciones culturales rurales previas, más antiguas y primordiales, asociadas sin más precisión a un tipo social y ubicadas temporalmente en la colonia. Tanto una como otra argumentación poseían flancos visibles y eran, en un sentido, invenciones $(. .$.$) . En principio, (...) todas ellas remiten al pasado; [\mathrm{y}] \mathrm{su}$ eficacia en la creación de sentido común no depende de su respaldo empírico o de su rigor científico, sino, una vez más, de condiciones político-culturales presentes, que impactan en su circulación y recepción. Por otra parte (...), en muchas intervenciones de intelectuales, a la hora de la acción estatal, en particular la escolar, y de los productos de la cultura de masas, ambas aparecían mezcladas y articuladas, sin mayor tensión. La nación de Mayo se cruzó allí con la nación del gaucho, figura ya admitida por el Estado en la segunda mitad de los años treinta, mucho tiempo después de que ello ocurriera entre los sectores populares (...) (pp. 73-74).

Es, en parte, bajo este encuadre que debe ser interpretada la irrupción de Rosas en la agenda pública de esos años y bajo el prisma de lo que Cattaruzza (2007) denominó «usos del pasado». Estos comprenden una variedad de imágenes, representaciones y evocaciones que pueden ser concebidas como puntos de condensación de un proceso de interpretación del pasado con el fin de intervenir en ellas tornando legítimas las posiciones presentes e influyendo en las coyunturas en las cuales se desenvuelven.

Entendemos que buena parte de los análisis que han atendido al vínculo entre la música popular y los usos del pasado se han concentrado en casos donde las producciones consideradas han tenido cierta afinidad tácita con un determinado encuadre historiográfico o ideológico. Inscribimos allí los estudios sobre los debates de fines de los años sesenta en 
torno a la manera de representar a los caudillos populares del siglo XIX, en el marco del auge de la música de raíz folklórica (Mamani, 2015); pasando por las vinculaciones estrictas entre revisionismo histórico y música popular para la misma época (Stortini, 2004); hasta aquellos análisis de más largo aliento que han abordado este problema atendiendo al éxito de audiencias que ese mismo género tuvo durante la década del setenta (Molinero, 2011). Ello ha redundado también en una especial atención a estos problemas para la segunda mitad del siglo XX. Existen otras vías interpretativas, como las planteadas por Chamosa (2012) y Karush (2013) que, atendiendo a distintas facetas, analizaron la compleja trama de elementos que se articularon en torno a la música, como vector de nacionalidad. Por su lado, Chindemi y Vila (2017) estudiaron el proceso por el cual la llamada «canción criolla» de las primeras décadas del siglo XX se fue consolidando como «repertorio nacional», dando cuenta del contrapunto entre música popular, criollismo y nación durante esos años, antes de que el tango hegemonizara la escena.

En relación con lo anterior, creemos que existieron en el ciclo federal elementos vinculados a una estética criollista en una coyuntura donde esa forma expresiva ocupó un lugar central en los imaginarios nacionales y habilitó - tal como lo expresó Cattaruzza- a edificar otro centro posible de la tradición argentina. Un centro con eje en el gauchaje que supo conjugarse bien con la figura de Rosas y con su época. Estas formas de representar los años de la Federación pusieron el acento, sobre todo, en los fenómenos de la cultura popular: qué sucedía en los carnavales, los mercados y las pulperías, entre payadores, mulatas y mazorqueros. Tal como lo ha afirmado Héctor Pedro Blomberg, autor de la mayoría de las letras que formaron parte del repertorio federal de Corsini: «No me interesó Rosas por sí mismo, a pesar de su sombría y trágica grandeza personal, sino su época: los tipos, las costumbres, los cantos, los lugares sobre los cuales caía la roja sombra del Restaurador».

Dichas representaciones gozaron de mucha popularidad entre el público. Vale traer aquí un comentario vertido en las páginas de El Diario a mediados de 1934:

El caso de Rosas es un verdadero «caso». Mientras se multiplican los libros sobre su actuación, libros que aun sin quererlo están haciendo a Rosas una justicia póstuma bastante distinta a la justicia histórica, mientras en la radio, en el teatro, en los festivales, las poesías y música populares, la figura del Héroe de la Expedición del Desierto, goza de una presencia y de una aureola extraordinaria (la épica del 
periodo rosista es aprovechada al $100 \times 100$ por todas esas formas del arte y del pseudo-arte) en el recinto amurallado de la historia oficial, de las efemérides oficiales y de la memoria oficial, se quiere echar sobre Rosas una capa de olvido, completamente inútil por otra parte, porque la figura de Rosa se sale a cada rato de su lejana tumba de Southampton y cubre con su sombra la memoria del país.

En un trabajo que oficia de antecedente importante para nuestro análisis, Adolfo Prieto (1959) afirmó que tanto la «permanencia del tema» para aquellos años, así como lo que entonces garantizaba su pervivencia, se podía explicar por la «compartida necesidad de revivir, míticamente, la existencia de un pasado trágico; y la intuición de que el proceso desencadenado por el episodio rosista» tenía «todavía abiertas sus instancias» (p. 41). En ese sentido, vale retomar lo planteado por Carolina González Velasco (2018) para el caso del teatro, prestándole atención al modo en que «la política» fue tematizada en los escenarios durante las dos décadas posteriores a la sanción de la Ley Sáenz Peña, al afirmar que estas representaciones pueden haber funcionado como «caja de resonancia» de ciertos problemas de la época, pero también como una «usina particular para generar otras imágenes o discusiones», o bien simplemente para instalar esta temática como un «repertorio informativo» ( $\mathrm{p}$. 227).

En consonancia con lo anterior, nos interesa remarcar aquí que la empresa de reivindicación rosista del revisionismo, que tomó mayor vigor a partir de los años treinta, no debe ser vista de modo aislado, sino en interacción con un cúmulo de composiciones que tornaron disponibles una cantidad de imágenes de Rosas y su época, mayor a la que había circulado hasta el momento. Estas producciones -en especial si tenemos en cuenta su popularidad- están lejos de poder ser vistas como marginales frente a la labor de un puñado de intelectuales que parecían -en muchos casos- no estar preocupados aún por interpelar a grandes públicos.

\section{Rosas y sus representaciones}

Expondremos aquí sintéticamente la manera en que la historiografía analizó el problema de la reposición pública de la figura de Rosas y su época en los años treinta. Tanto el trabajo de Diana Quattrocchi Woisson (1995) - precursor en la materia- como el de Michael Goebel (2013), procuraron elaborar una crítica sobre el arsenal revisionista, pero 
terminaron por asumir efectivamente sus postulados, al plantear que la Argentina había tenido una historia «oficial», hasta que el revisionismo llegó a ponerla en jaque, al afirmar que había «otra historia». En los argumentos de ambos la figura de Rosas ganó centralidad. Para la primera, como «verdadero instrumento de contrahistoria» (Quattrocchi Woisson, 1995, p. 81). Para el segundo, en tanto evocación central del «nacionalismo», en el marco de lo que consideró una matriz interpretativa «biculturalista» de la identidad nacional, separada entre las tradiciones político-culturales: «liberal»y «nacionalista» (Goebel, 2013, p.287). Por su parte, Fernando Devoto y Nora Pagano (2009) repararon en que:

cualquier definición [de revisionismo] que elijamos, sólo puede ser entendido en una dinámica temporal, a la vez como una secuencia de etapas y como una tradición acumulativa de rasgos, problemas y elementos identificatorios. A la manera de un rio correntoso, las sucesivas épocas revisionistas se dilatan, se contraen, se reformulan, se combinan con diferentes contextos políticos y culturales y a la vez sedimentan en un conjunto de motivos y de lugares de memoria que sirven a los partícipes para identificarse. En esa flexibilidad puede quizás encontrarse una de las razones de su perdurabilidad. (pp.202203)

Consecuentemente, procuraron observar la pluralidad de autores que han sido contemplados dentro de esta definición y, en ese sentido, la pluralidad de interpretaciones a las que -dependiendo de quién lo expresara, cuándo y por qué- puede consignarse el mote de revisionista. A nuestros fines, es importante resaltar que Pagano y Devoto (2009) ponderaron el proceso expansivo de públicos lectores durante la década de 1920 y ubicaron allí, en el consumo de «cuestiones y controversias históricas en un formato ciertamente no académico sino entre la divulgación y el folletín», un emergente donde la figura «controversial» de Rosas ganó interés (p.209).

Por su lado Tulio Halperín Donghi (2003) ha sido sumamente perspicaz en el análisis sobre el modo en que se imbricaron la «crisis» atravesada por la Argentina de fines de la década del veinte, consistente en haber «descubierto» su desplazamiento del destino de grandeza imaginado hasta entonces, y la creciente «tormenta del mundo» desenvuelta en esos años. Particularmente, en lo que nos interesa aquí, le dedicó allí un importante trabajo a explorar los efectos que ese proceso tuvo en la 
construcción de una imagen alternativa de la experiencia histórica argentina. En sus propias palabras, haciendo alusión al curso tomado por el país a partir de 1930, afirmó que:

quienes emprendían el examen eran los marginados por el orden político que dominaba el presente argentino, y estaban de antemano dispuestos a buscar en su exploración del pasado nacional los materiales para una implacable acta de acusación contra las corrientes y tradiciones políticas de las que ese orden se proclamaba orgullosamente heredero. (p. 52)

Matizando esta perspectiva, Darío Macor (1995) puso mucha atención sobre la invención de la década del treinta en el debate político intelectual de la Argentina sesentista. Allí buscó horadar la naturalización de la «década del treinta» como unidad de sentido, para dejar expuesto que «su invención» resultó ser:

producto del debate político/ideológico que, provocado inicialmente por el quiebre del «consenso liberal» acelerado precisamente por la gran crisis con la que se inicia la década, alcanzará su mayor densidad a partir de la caída de Perón y hasta bien entrada la década del setenta(p. 2)

En diálogo con la operación que señaló Macor, creemos que es dable matizar el lugar que algunas imágenes de la «década del treinta» le otorgaron a Rosas y prestar atención a que esa «invención» pudo haber aplastado otras de sus imágenes que se encontraban en circulación en esos años, por jerarquizar el rol de la historiografía revisionista. En ese sentido, si bien existen excepciones (Adamovsky, 2019; Cattaruzza, 2007), ha sido prácticamente nula la atención al fenómeno que analizamos aquí a la hora de explicar las razones de esa reposición. En este punto, vale hacer una mención a un artículo reciente de Sylvia Saítta (2019). Si bien focalizado en «los usos de la historia» en los radioteatros guionados por Blomberg durante los años treinta y cuarenta, que tuvieron por tema la cultura popular durante la época de Rosas, va absolutamente en consonancia con lo que aquí planteamos.

Por último, cabe subrayar el trabajo realizado por la historiadora inglesa Lauren Rea (2013). Coincidimos con ella plenamente en la necesaria ponderación del fenómeno de consumo masivo que resultaron ser las producciones de Blomberg -una vez más, esta autora prestó atención 
especialmente a los radioteatros, pero también se incluyeron allí las composiciones del cancionero federal-sumado a una coincidente voluntad de reflexionar sobre este fenómeno en diálogo con las maneras en que el pasado fue representado en el propio contexto de su producción: los años treinta y cuarenta. Pero disentimos con su interpretación, a nuestro entender demasiado lineal y esencialista de la obra de Blomberg, al inscribirla en una saga literaria que tendría por antecedentes directos a Amalia -de José Mármol- y las novelas de temática rosista de Eduardo Gutiérrez. Más aún, creemos que ni siquiera existe un trayecto lineal entre haberse reconocido como «anti-rosista» y encuadrarse dentro de los parámetros de la «historia oficial» o la «historia liberal», tomando los términos que la autora homologó en su trabajo.

Si bien nuestra investigación asume la circulación de representaciones como un dato de la realidad, busca afincar en sus puntos de interacción y por lo tanto disiente con las miradas que diseccionan los ámbitos de la realidad como compartimentos estancos, entendemos que abordar este fenómeno con las categorías del debate historiográfico, sin mediación, resulta problemático. Incluso si en algún caso fuera posible identificar las representaciones a las que aquí atendemos bajo posiciones ubicables en la dicotomía que contrapuso a revisionistas y liberales, debemos dar lugar a las ambivalencias a la hora de reflexionar sobre los impactos que esos mensajes pueden haber tenido sobre dicha sociedad.

\section{Un ciclo de canciones federales en la música popular de los años trein- ta}

Buscaremos aquí dar cuenta de la prolífica producción de canciones de temática federal en la música popular, entre fines de los años veinte y principios de la década del cuarenta. Dicho ciclo tuvo sin duda una voz protagónica, la de Ignacio Corsini acompañado por las guitarras de Enrique Maciel, Armando Pagés y Rosendo Pesoa. Pero no fue la única, ya que estas composiciones fueron cantadas también por Carlos Gardel, Ada Falcón, Agustín Magaldi y Félix Rodríguez. Si bien en su enorme mayoría las canciones a que prestamos atención fueron compuestas por Héctor Pedro Blomberg y Enrique Maciel (con alguna contribución de Carlos Max Viale Paz o Vicente G. Retta) también las hubo de Francisco Canaro, del dúo Homero Manzi-Sebastián Piana, entre otros. Trataremos de dar cuenta del devenir de dicho fenómeno que se desa- 
rrolló al compás de la importante centralidad que tomó el problema de los ritmos musicales como expresión de la nacionalidad.

Desde distintos ámbitos, en la Argentina posterior al centenario sobrevoló la importante tarea de suturar una identidad nacional. La música no se mantuvo ajena a esa empresa. En este sentido, compartimos con Chindemi y Vila la perspectiva de entender a cierto cancionero popular de las primeras décadas del siglo XX bajo la denominación de «canción criolla», partiendo de la «mixtura» de los repertorios (prestando atención a las letras, los ritmos e incluso las vestimentas utilizadas para las puestas en escena) que interpretaban los llamados «cantores nacionales» de aquellos años: Carlos Gardel, Rosita Quiroga, Ignacio Corsini y Agustín Magaldi, los cuales contenían tanto música citadina (identificada con el tango), como música que luego sería identificada como folklórica (pero que en ese momento era llamada campera, criolla, etc.). Esta matriz «criolla» contenía contrapuntos entre la ciudad y su campaña, pero su asiento no era indistinto sino de cuño fundamentalmente «pampeano». Era desde ese lugar que buscaba erigirse como música nacional. Con estos argumentos, Vila y Chindemi (2017) han discutido con la idea de cierta «evolución lineal» desde la canción criolla hacia el tango, ya que el tango convivió dentro del continente de la música criolla, como un género más junto a otros, hasta ganar una autonomía mayor desde la que hegemonizó el sentido de la música popular nacional a fines de los años treinta.

Ignacio Corsini, uno de los cantores nacionales, fue la figura central del cancionero federal. Contaba en su repertorio con clásicos del tangos como «Malevaje», «Yira yira» o «Caminito», pero también los homenajes a payadores célebres, como la milonga «El adiós de Gabino Ezeiza»-dedicada al prolífico payador negro de fines del siglo XIX- de Blomberg y Maciel o «Betinotti» de Homero Manzi, dedicado a José Betinotti quien fue bautizado como «el último payador». También grabó «Caminito del indio» de Atahualpa Yupanqui en 1941. Nació en Sicilia Italia- el 13 de febrero de 1891 y llegó a la ciudad de Buenos Aires en 1896. En 1897 se trasladó junto con su familia a Carlos Tejedor.

En 1907 se asentó en Buenos Aires y comenzó a probar suerte como cantor en pulperías y cafetines de la ciudad y sus alrededores. Así conoció a los hermanos Podestá y se les sumó. Esa compañía le dio mayor exposición y así llegó incluso a grabar en 1917 la película dirigida por Atilio Lipizzi Federación o muerte. En 1921 fue contratado por Julio Traversa para integrar la compañía teatral de César Ratti, en el Tea- 
tro Apolo. Allí cantó, en 1922, «El patotero sentimental» en el marco del sainete El bailarín del cabaret, lo cual le otorgó un gran reconocimiento entre el público. Si bien Corsini ya contaba con 30 años y algunos discos publicados en su haber, la grabación de esta canción con la Orquesta de Roberto Firpo pareciera haber sido un punto de ruptura en su carrera.

A partir de entonces su presencia en dicho teatro pasó a ser prácticamente permanente formando parte de distintas compañías hasta el año 1926. Allí trabajó, entre otros, junto a Alberto Vacarezza. Unos años después pasó a conformar la compañía de Luis Arata al Teatro Cómico. En 1928 se desvinculó de las compañías teatrales y lanzó su carrera solista como cantor en el teatro Astral con gran éxito de público. Ese mismo año actuó por primera vez en la radio. Ya desde esas primeras actuaciones percibió una suma «respetable» para la época por audición actuando para la radio Nacional (devenida en Radio Belgrano en 1935). En abril de 1929 cantó «La pulpera de Santa Lucía» en el Teatro Apolo y unos días después sonó por primera vez, con gran éxito, en radio Prieto. Este fue el hito de inicio del llamado «ciclo federal» de su carrera. Enrique Maciel, quien le puso música a la lírica de Blomberg, y además quien fuera- tal como lo dijimos anteriormente- guitarrista central de Corsini en su carrera solista, reconstruyó en una entrevista de 1946 la historia del vals «que en determinado momento cantó toda la población, no ya de Buenos Aires, sino del país». El guitarrista compuso la música sobre la letra de Blomberg y la presentó en un ensayo de la obra La sangre de las guitarras frente al empresario Pascual Carcavallo, la actriz Elsa O’Connor y los músicos Salvador Merico y José Lozzi. En esa ocasión la canción fue rechazada pero, agregó Maciel:

quiso la suerte que apareciera en mi camino Ignacio Corsini, quien la estrenó en una radio, con suceso insospechado aun para mí, tanto que se dio el caso de un público reclamando «bis» por teléfono, por correspondencia y hasta personalmente.

Para concluir que:

Salieron a la venta quinientos mil ejemplares y se imprimieron ciento cincuenta y siete mil discos, todo lo cual me significó, en concepto de derechos de autor, la entonces fabulosa suma de veinte mil pesos... Y cuando el éxito era ya indiscutible y no había cancionista, cantor, ni muchacho con sueños de serlo, ni habitante de cualquier sexo y edad que dejara de cantar o silbar «La pulpera», se cruzó otra 
vez en mi camino Pascual Carcavallo, diciéndome: «-Con usted me equivoqué una vez, pero no he de equivocarme más».

El éxito de esta canción fue inmenso. El simple, del sello Odeón, en el que Ignacio Corsini grabó en 1929 «La pulpera de Santa Lucía», llevaba en el lado B «La Mazorquera de Monserrat», donde también se evocaban los años de Rosas. La voz de Corsini se acompañó allí del trío de guitarras que trabajarían junto a él por los próximos veinte años. En 1930 grabó otra canción de temática federal, el vals «La Virgen del Perdón», esta vez con música de Carlos Vicente Geroni Flores, letra de Vicente G. Retta y Carlos Max Viale Paz. A diferencia de las canciones anteriores, esta estuvo dedicada a Manuelita Rosas, a quien elogiaba:

Mi niña Manuelita es una santa, la adoran de Palermo a Montserrat, y es tan linda que al verla a mí me encanta, cuando del brazo del tatita va...

A lo que agregarán luego, una nota de importancia sobre su relación con «los pobres»:

Es su ángel de la guarda Manuelita, y la ley no resiste a su bondad, para los pobres es la madrecita que a manos llenas su ternura da.

Para entonces, «La virgen del perdón» ya había sido popularizada el año anterior en las versiones grabadas por Ada Falcón con el acompañamiento de la Orquesta de Francisco Canaro, Libertad Lamarque y el dúo Carlos Gardel-José Razzano. Ese mismo año, Corsini volvió a grabar una canción que tematizaba la época de Rosas, compuesta por Blomberg y Maciel: el vals «La guitarrera de San Nicolás», donde se contaba la historia de una payadora federala que había conmovido incluso a la mazorca.

El derrotero del ciclo continuó cuando en 1931 Corsini grabó «Tirana Unitaria»y, un año después, «La bordadora de San Telmo». En ambas apareció nuevamente el protagonismo de una mujer en el relato de la canción. La primera, contaba la historia de una unitaria puesta a protección de la mazorca, por su enamorado que dejaba Buenos Aires para ir al Uruguay con Manuel Oribe y añoraba un día reencontrarse con 
ella «en la tierra del Restaurador». La segunda, por su parte, puso el foco concretamente en la historia de Paulina Varela, quien fuera la protagonista de la novela La mulata del Restaurador. Incluso formó parte de la versión teatral de la obra. Allí le cantaba a «la bordadora del viejo San Telmo», que «bordaba las rojas divisas» de la Federación. En 1932 «el caballero cantor» grabó «El payador de San Telmo», vals que fue la segunda parte de «La pulpera de Santa Lucía» y llevó letra y música de José Lojo.

La canción titulada «La parda Balcarce», con letra de Blomberg y Viale Paz y música de Enrique Maciel, fue grabada también en 1932 por el dúo Agustín Magaldí-Pedro Noda. Dicha composición insertó un tópico central del cancionero federal: los carnavales en tiempos de Rosas. Éstos, o más bien las «fiestas federales», pueden haber persistido con fuerza en la memoria popular de aquellos años, más aún si tenemos en cuenta la fuerte capacidad ritualizadora que estas festividades habían tenido unas ocho o nueve décadas antes y la función que pueden haber cumplido para que aquel pueblo se imaginara a sí mismo como parte de una comunidad en construcción que los excedía, capaz de llamarse nación, patria o bien Santa Federación (Salvatore, 1996).

Volviendo sobre la canción, comenzaba con el recitado:

Abuelita Dominga, reina de los candombes, enséñeme la copla de la parda Balcarce, que el carnaval de Rosas esta noche se acaba, y mi guitarra quiere cantarla como nadie.

Allí se relataba en una estructura narrativa similar a otras de este repertorio, una historia de amor dramático entre una mujer federal y un hombre unitario, esta vez inscripto en las celebraciones del carnaval:

Por andar con unitarios

lo mandaron fusilar,

fue en un carnaval de Rosas

cuando ella lo vio pasar.

Murió inválido entre cuatro

negros del Restaurador,

y recién supo Martina

que aquel mozo era su amor.

Para concluir: 
Y otro carnaval de Rosas, besó con ansia mortal al hijo del fusilado y se ensartó en un puñal. Cuando murió la Martina quedó el hijo de su amor, negras y blancas lloraban, en el Barrio del Tambor.

El tema del carnaval, así como la figura de Abuelita Dominga, volvería a aparecer en la lírica de Blomberg. En 1933 Corsini grabó otro tema que vale incluir dentro de esta serie: el vals «La canción de Amalia», que narraba la historia de la protagonista de la homónima novela de José Mármol.

En 1935, tras la muerte de Carlos Gardel, la revista de circulación nacional El Suplemento lanzó una encuesta entre sus lectores a fin de elegir al «Príncipe de la canción porteña». Ignacio Corsini fue galardonado con el primer puesto luego de recibir 87.643 votos a favor, en una elección que tuvo 829.783 sufragios. Hacía seis años que Corsini le daba un fuerte protagonismo a las canciones de temática federal y lo seguiría haciendo. Con ánimo de subrayar su enorme éxito comercial, vale remarcar que para 1938 ganaba unos siete mil pesos mensuales, lo que representaba uno de los mayores ingresos por ese trabajo para la época (Ulanovsky, 1995, p. 105). Ese mismo año Blomberg y Maciel volvieron al ruedo con «Bailecito del sur», que sería popularizado tiempo después por Enzo Valentino. Allí relataron las semblanzas de «los colorados de Rosas». En 1939 Corsini volvió a grabar una nueva canción escrita por Blomberg y musicalizada por Maciel titulada «China de la mazorca», en la que aparecía una vez más el tema del carnaval:

China de la mazorca, todos la llaman restauradora, porque ella lleva prendida al pecho, la flor de sangre de la divisa de Buenos Aires.

Viva Rosas, pira santa

cantaban de corazón

y en los barrios los candombes

repetían la canción.

iTu rurru tururu!

iTu rurru tururu!

iTu rurru tururu! 
Dos años después grabó «Abuelita Dominga», la cual ofició de segunda parte de «La parda Balcarce», que Magaldi había grabado en 1932. Esta composición describía las añoranzas de su amor en los tiempos del carnaval de Rosas, antes de morir:
Abuelita Dominga era muy vieja
y vivía en el barrio de los candombes.
Del carnaval de Rosas no se olvidaba
al cantar esta copla roja de amores.

Esta milonga aludía nuevamente al mundo de los negros del «Barrio del tambor».

Ya entrada la década del cuarenta Corsini no volvió a grabar composiciones de Blomberg y Maciel. Hacia 1946 realizó la última de sus grabaciones para cantar por última vez en Radio Belgrano el 28 de marzo de 1949. Enrique Maciel, por su parte, puso al aire de Radio Argentina, en junio de 1942, un programa, junto con Azucena Maizani y «Lopecito», denominado «Tangos y candombes». Allí, según una nota periodística de la época:

La Federación, con sus tintes rojos, sus conspiradores románticos y decididos y sus tamboriles es el primer eslabón de cada una de esas medias horas que se irradian los miércoles, viernes y sábados. El último cuarto de hora está destinado a la evocación de los patios porteños del 900 , a sus tangos bravíos (...).

Para concluir, agregó:

Enrique Maciel, cuya orquesta típica y de la Federación constituye una novedad absoluta en los programas radiales, expresa en su gran conjunto orquestal melodías que a fuer [sic] de viejas resultan nuevas para el gran público que no tenía oportunidad de conocerlas.

Maciel siguió componiendo y grabando discos de pasta, que contenían dos temas cada uno, que fueron luego compilados en un disco a fines de los años cincuenta y los primeros sesenta, titulado Tangombe de Buenos Aires. Allí siguió desarrollando la temática federal y registró una nueva versión de «La mazorquera de Monserrat», además de «Bailecito del sur» (también de Blomberg y Maciel), «Urquiza»y «La flor federal», con letra de Arsenio Mármol. 
Las canciones federales de las que aquí hemos dado cuenta, junto con muchas otras que no hemos introducido por una cuestión de espacio, siguieron sonando durante las décadas siguientes. Algunas de ellas, como «La pulpera de Santa Lucía», se convirtieron en parte insoslayable del cancionero popular argentino. Otra, como «Barrio viejo del ochenta» que se mantuvo inédita en los años cuarenta, fue popularizada en la década siguiente por las orquestas de Aníbal Troilo (con la voz de Jorge Casal) y Roberto Pansera (con la voz de Enzo Valentino).

Héctor P. Blomberg siguió publicando relatos y notas en revistas de interés general, y falleció el 3 de abril de 1955. Enrique Maciel, que tal como lo afirmamos anteriormente, siguió componiendo música y tocando junto a Corsini hasta el momento de su retiro, falleció el 24 de enero de 1962. Con motivo de su muerte, desde las páginas de La Razón, aseguraron que:

«Letra de Héctor Pedro Blomberg y Música de Enrique Maciel» fue y será aun después de la desaparición de ambos una marca registrada indeleble. Entre los dos raptaron del olvido al legendario barrio de San Telmo y sus tradiciones del tiempo del Restaurador. Con canciones como «La pulpera de Santa Lucía» o «La mazorquera de Monserrat», Enrique Maciel demostró hasta donde el auténtico folklore puede mantener a través del tiempo una temática llena de símbolos sugerentes que «llegan»-adornados con los prestigios del arte- al alma colectiva.

El «caballero cantor» volvió a aparecer en escena en 1959 en un programa televisivo, por única vez luego de su retiro en 1949, y falleció finalmente el 26 de julio de 1967.

\section{Conclusiones}

En 2018 el Cuarteto Cedrón presentó su disco Jamaica Marú. A propósito del mismo, que buscó ser un homenaje a la obra de Blomberg, Juan Carlos «El Tata» Cedrón afirmó en una entrevista:

Nací en el '39, entonces de pibe había mucha radio y se escuchaban cosas anteriores, del '30, como «La pulpera de Santa Lucía». Con la radio descubrimos que Blomberg había hecho con Maciel una obra enorme, que no era un solo tema, sino un montón, con barcos y 
marineros primeros, con la época de Rosas después, federales y unitarios. Las canciones populares te despertaban el interés por saber qué había pasado.

El conjunto de elementos vertidos a lo largo de estas páginas, en consonancia con estas palabras, sirven para arriesgar algunas reflexiones sobre ciertos efectos que el ciclo de canciones federales pudo haber tenido, tanto para la coyuntura en la cual se insertó, como para las décadas siguientes. Estudiar la recepción en el pasado siempre es un trabajo difícil. No son de ese orden las conclusiones que pretendemos verter aquí, sino más bien subrayar -una vez más- que el cúmulo de composiciones del que acabamos de dar cuenta se mantuvo productivo y en escena durante algo más de una década, colaboró a poner en escena una gran cantidad de representaciones de la época de Rosas - sin duda, mayor a la que había circulado hasta entonces- y pudo haber dejado una fuerte huella en sus escuchas.

Afirmamos esto por las ventas y premios de los cuales hemos dado cuenta aquí y que como afirmó Frith son un objeto de medida posible de la popularidad, pero también por los géneros y temas que este ciclo puso en escena en una coyuntura crucial en lo que hace a la búsqueda de elementos estéticos capaces de expresar lo nacional. Las representaciones de la época de Rosas, más allá de las interpretaciones al respecto, se conjugaron bien con un imaginario nacional en clave criollista que estaba en auge. En consonancia con lo anterior, vale prestarle atención también al hecho de que figuras tan disímiles como Palito Ortega, Roberto Rimoldi Fraga o Antonio Tormo hicieron suyas interpretaciones del repertorio de Corsini en las generaciones siguientes.

Esto sucedió mientras los círculos historiográficos abocados a estos temas discutían en buena medida en torno a la pertinencia de poner en valor la figura de Rosas. Más allá de los matices que esos debates pueden haber tenido en dichos ámbitos, entendemos que una mirada integral sobre la manera en que este pasado irrumpió sobre el presente de aquella sociedad, necesariamente debe prestar atención a un fenómeno que, todo indica, fue más que un ruido de fondo. No queremos decir con esto que el «ciclo federal» haya oficiado como «banda de sonido» del rosismo de esos años. Todo transcurrió de una manera mucho más ambivalente y contradictoria. 


\section{Referencias bibliográficas}

Adamovsky, E. (2019). El gaucho indómito: de Martín Fierro a Perón, el emblema imposible de una nación desgarrada. Buenos Aires, Argentina: Siglo XXI.

Cattaruzza, A. (2007). Los usos del pasado. La historia y la politica argentinas en discusión, 1910-1945 .Buenos Aires, Argentina: Sudamericana.

Cattaruzza, A. (2017). El pasado como problema político. Anuario IEHS, 32, 59-78.

Chamosa, O. (2013). Breve historia del folclore argentino (1920-1970). Identidad, politica y nación. Buenos Aires, Argentina: Edhasa.

Chindemi, J. y Vila, P. (2017). La música popular argentina entre el campo y la ciudad: música campera, criolla, nativa, folklórica, canción federal y tango. ArtCultura, 19 (34).

Devoto, F. y Pagano, N. (2009). Historia de la historiografía argentina. Buenos Aires, Argentina: Sudamericana.

Frith, S. (2001). Hacia una estética de la música popular. En: Cruces Villalobos, F. (Ed.). Las culturas musicales: lecturas de etnomusicología, pp. 413-436. Madrid, España: Trotta.

González Velasco, C. (2018). Otros escenarios para la política en los años veinte: el teatro de género chico. En: Gayol, S. y Palermo, S. (Eds.), Politica y cultura de masas en la Argentina de la primera mitad del siglo XX. Los Polvorines, Argentina: UNGS.

Goebel. M. (2013). La Argentina partida: Nacionalismos y politicas de la historia. Buenos Aires, Argentina: Prometeo.

Halperín Donghi, T. (2005). El revisionismo bistórico argentino como visión decadentista de la historia nacional. Buenos Aires, Argentina: Siglo XXI.

Karush, M. B. (2013). Cultura de clase. Radio y cine en la creación de una Argentina dividida (1920-1946). Buenos Aires, Argentina: Ariel.

Macor, D. (1995). Imágenes de los años treinta. La invención de la década del treinta en el debate político intelectual de la Argentina sesentista. Documento de Trabajo $n^{o} 3$, Programa de Estudios Interdisciplinarios de Historia Social. Santa Fe, Argentina: UNL.

Mamani, A. (2015). Caudillismo, música folklórica y usos políticos del 
pasado. Félix Luna y la polémica historiográfica en torno a Los Caudillos. Cuadernos de Historia. Serie economia y sociedad, 13/14, 247-263.

Molinero, C. (2011). Militancia de la canción. Politica en el canto folklórico de la Argentina (1944-1975). Buenos Aires, Argentina: Ediciones de Aquí a la vuelta/ Ross.

Prieto, Adolfo (1959). Proyección del rosismo en la literatura argentina. Rosario, Argentina: UNL.

Quattrocchi Woisson, D. (1995). Los males de la memoria. Historia y politica en la Argentina. Buenos Aires, Argentina: Emecé.

Rea, L. Argentine Serialised Radio Drama in the Infamous Decade, 19301943: Transmitting Nationhood. Farnham, Inglaterra: Ashgate.

Saítta, S. (2019).Los usos de la historia en los comienzos de la radio argentina. Revista Latinoamericana de Ciencias de la Comunicación, 18 (32), 326-337.

Salvatore, R. (1996). Fiestas Federales: Representaciones de la República en el Buenos Aires rosista. Entrepasados, 11, 45-68.

Smith, A. (2009). Ethno-Symbolism and Nationalism. A Cultural Approach. New York, Estados Unidos: Routledge.

Stortini, J. (2004). Polémicas y crisis en el revisionismo argentino: el caso del Instituto de Investigaciones Históricas «Juan Manuel de Rosas». En Devoto, F. y Pagano, N. (Eds.). La historiografía académica y la historiografía militante en Argentina y Uruguay, pp. 81-106. Buenos Aires, Argentina: Biblos.

Ulanovsky, C. (1995). Dias de radio (1920-1959): historia de los medios de comunicación en la Argentina. Buenos Aires, Argentina: Emecé. 